\title{
Predation on settling bivalve larvae by benthic suspension feeders: the role of hydrodynamics and larval behaviour
}

\author{
C. André ${ }^{1}$, P. R. Jonsson ${ }^{2}$, M. Lindegarth ${ }^{2}$ \\ ${ }^{1}$ Department of Zoology, Stockholm University, S-106 91 Stockholm, Sweden \\ ${ }^{2}$ Tjärnö Marine Biological Laboratory, S-452 96 Strömstad, Sweden
}

\begin{abstract}
Predation by the suspension-feeding infaunal bivalve Cerastoderma edule on settling $C$. edule larvae was studied in a flume boundary-layer flow. The density of settled larvae was reduced by $33 \%$ in an area of $5 \mathrm{~cm}^{2}$ enclosing individual adults. Mean survival time for competent $C$. edule larvae drifting over sediment populated with feeding adults ( $380 \mathrm{ind} . \mathrm{m}^{-2}$ ) was $64 \mathrm{~s}$, and $75 \%$ of the observed larvae were inhaled by adults. Observations of the siphonal currents produced by $C$. edule and the swimming behaviour of larvae were combined in a computer model to assess the importance of adult density and boundary-layer flow on the predation risk experienced by settling larvae. Survival of settling larvae decreased drastically with increasing adult density, whereas increased flow velocity caused only a slightly higher predation risk. Although reduction in larval settlement on the scale of individual adults may be small or moderate, inhalation of settling larvae by populations of resident suspension feeders may cause a significant decrease in settlement on a larger scale $\left(10^{1}\right.$ to $\left.10^{3} \mathrm{~m}\right)$.
\end{abstract}

\section{INTRODUCTION}

It has long been recognized that the recruitment success of bivalve larvae is often negatively correlated with high densities of infaunal suspension-feeding bivalves (Smidt 1944, Kristensen 1957, Hancock 1973, Beukema 1982, Möller 1986, Jensen 1992). Field experiments, however, have demonstrated only moderate reductions in the settlement and recruitment of larvae in dense assemblages of adult bivalves (Hines et al. 1989, André \& Rosenberg 1991, Bachelet et al. 1992).

The major mechanism proposed is predation by adults that entrain settling larvae in their feeding currents (Thorson 1950, Woodin 1976). Infaunal suspension-feeding bivalves create strong feeding currents and may process several litres of water per hour, and laboratory experiments have shown that adult bivalves readily inhale swimming larvae (Kristensen 1957, review in Young \& Chia 1987). Predation on larvae could, however, be confounded with other processes that produce similar distributional patterns, such as pre-emption, allelopathy, larval be- haviour and flow effects caused by the residents (Young 1990). Pre-emption is not likely to be important for bivalves in soft sediments since adults usually dwell deeper down in the sediment than do newly settled larvae and juveniles. Studies on the importance of chemical substances for the settling of invertebrate larvae have mainly focussed on promotive effects (reviews in Crisp 1974 and Butman 1987), while the inhibition of settling and metamorphosis has received less attention (see, however, Young \& Chia 1981, Standing et al. 1984, Woodin 1985, Ritchoff et al. 1986, Davis \& Wright 1988, Davis et al. 1989).

Part of the ambiguity regarding the importance of adult-larval interactions in suspension feeders is also due to the fact that the methods used, i.e. correlative investigations, field experiments and laboratory studies, are on different spatial and temporal scales (Black \& Peterson 1988, Young 1990, André \& Rosenberg 1991). Provided that settling larvae inhaled by a suspension feeder do not survive, the strength of the adult impact on settlement is determined by the probability of encounter between settling larvae and feeding adults. The encounter rate will vary with adult 
density, patch size (Black \& Peterson 1988, Ertman \& Jumars 1988), the radius of influence of individual adults (Young 1990) and movements (active or passive) of the larvae (Butman 1987). Young (1990) suggested from theoretical arguments that the local influence of individual suspension feeders on larval settlement is expected to be weak, and indeed Ertman \& Jumars (1988) found no reduction in settlement of larval mimics around the siphons of the infaunal bivalve Clinocardium nuttallii. Although local effects may be small, predation on larvae by upstream bivalves in areas with extensive beds of suspension feeders may cause significant large scale-effects (cf. Peterson \& Black 1987). This has, however, not yet been tested in field experiments. Larval swimming during settlement and its interaction with fluid dynamics has recently received attention (Butman 1987, Jonsson et al. 1991, Pawlik et al. 1991). Jonsson et al. (1991) showed that bivalve larvae settling in moderate current speeds became trapped in the benthic boundary layer, and slowly drifted in the same direction as the water flow, at a height less than $1 \mathrm{~mm}$ above the bottom. This type of dntt may increase the encounter rate of suitable substrata, but should also result in a high susceptibility for larvae to predation by benthic suspension feeders.

The edible cockle Cerastoderma edule is a dominant suspension-feeding bivalve in shallow soft sediments all along the European Atlantic coast, and often reaches adult densities of up to several hundred $\mathrm{m}^{-2}$ (Beukema 1976, Möller \& Rosenberg 1983). In a field experiment André \& Rosenberg (1991) showed that high densities of $C$. edule reduced the settlement of conspecific larvae by $40 \%$. The aim of the present work is to investigate how the settlement of $C$. edule larvae on a bottom populated with adult cockles is influenced by adult feeding and fluid dynamics.

The study consists of 3 parts: Firstly, we described the flow pattern created by adult Cerastoderma edule; secondly, we studied the fate of settling larvae that slowly drifted over a bed of feeding adult cockles, and analyzed the distribution of settled larvae around adult siphon openings; thirdly, information on the feeding currents produced by the adult cockles and the swimming behaviour of the larvae (see also Jonsson et al. 1991) was combined in a finite-difference computer simulation to model the predation risk experienced by settling larvae.

\section{MATERIALS AND METHODS}

Flow field around adult cockles. The feeding currents produced by Cerastoderma edule (Linnaeus, 1758 ) were studied in both still and flowing water. In still water individual cockles were placed in glass aquaria (height $11 \mathrm{~cm}$, width $40 \mathrm{~cm}$, depth $20 \mathrm{~cm}$ ) with a $6 \mathrm{~cm}$ deep sediment layer on the bottom. To study the extension of the exhalant flow we used a taller aquarium (height $35 \mathrm{~cm}$, width $21 \mathrm{~cm}$, depth $11 \mathrm{~cm}$ ). Water temperature during the experiments was $17^{\circ} \mathrm{C}$ The feeding currents were observed through a horizontally mounted dissecting microscope, equipped with a video camera (Panasonic CCD-F10). Individual cockles were filmed both laterally and frontally. The video recorder (Panasonic NV-180) allowed a temporal resolution of 40 ms between frames, and the trajectories of the small particles present in the water were traced frame by frame on a transparent film covering the monitor screen. Measurements were made on a large number of particles, but to ensure that the particles represented flow lines in the plane of the screen, only those trajectories that produced the highest velocities were used in the analyses. In the lateral view, both siphons were in the same plane and the focus was set at the siphon centres, whereas in the frontal view separate projections were analyzed for the inhalant and exhalant currents. Lateral and frontal projections were then combined into a 3-dimensional symmetrical flow-field. Measurements were made on 6 individual specimens in the size range 15 to $43 \mathrm{~mm}$.

The effects of a unidirectional bottom current on the flow field produced by Cerastoderma edule were studied in a laboratory flume (for details about the flume see below and Jonsson et al. 1991), using the same video equipment as above. We traced particles moving over the sediment into the flow-field produced by individual cockles, and recorded the maximum height of inhaled streamlines above the bottom. These measurements were made on 2 cockles of the same length $(35 \mathrm{~mm})$ at a free-stream velocity of $5 \mathrm{~cm} \mathrm{~s}^{-1}$. We also measured how the height of the excurrent jet varied with free-stream velocity $(1,2,5,10$ and $15 \mathrm{~cm} \mathrm{~s}^{-1}$ ). This was accomplished by introducing fluorescein dye in the inhalant current and measuring the height of the exhaled plume of dye at a distance of $10 \mathrm{~cm}$ downstream of the cockles.

Fertilization and rearing of larvae. Adult Cerastoderma edule were collected at Tjärnö on the west coast of Sweden in early June 1990. Thirty cockles were individually placed in $200 \mathrm{ml}$ plastic beakers containing filtered $(0.2 \mu \mathrm{m})$ surface seawater $\left(26 \% \mathrm{~S}, 19^{\circ} \mathrm{C}\right)$. When a cockle spawned, usually within 1 to $2 \mathrm{~h}$, a small amount of egg or sperm was added to the other beakers to stimulate spawning. Eggs from 1 to 6 females were pooled and suspended in filtered seawater in 21 or $10 \mathrm{l}$ glass bottles. Sperm suspension was obtained by diluting the entire discharge of 1 male in $200 \mathrm{ml}$ seawater, and 4 or $20 \mathrm{ml}$ of sperm suspension, originating from 1 to 6 males, was added to the glass bottles and mixed with the eggs. The cultures were 
incubated at $15^{\circ} \mathrm{C}$ for 2 to $3 \mathrm{~d}$. Each day for the following $4 \mathrm{~d}$, hatched larvae were siphoned to new glass bottles, leaving undeveloped eggs and embryos on the bottom. The larvae were sieved, rinsed and transferred to fresh filtered seawater, and fed 50 to 100000 cells $\mathrm{ml}^{-1}$ of Isochrysis galbana every 2 to $3 \mathrm{~d}$. Between 17 and $21 \mathrm{~d}$ after fertilization, at a size of ca $280 \mu \mathrm{m}$, most larvae had a well-developed foot (pediveliger) and were able to settle (competent larvae).

Incubation with fluorescent pigments. Prior to each experimental run ca 20000 pediveliger larvae were transferred to a 2 l beaker containing suspended fluorescent particles (Radglo, Radiant color; mean size $4 \mu \mathrm{m}$ ). The larvae were allowed to feed on particles until the ingested pigment filled the gut region, usually within $2 \mathrm{~h}$. The larvae then fluoresced intensely when illuminated with blue light (Philips TLD $18 \mathrm{~W} / 08$ ) (see Lindegarth et al. 1991 for a detailed description of the labelling procedure).

Flume experiments. Experiments on the distribution of settled larvae around siphon openings of adult Cerastoderma edule, and on predation by adults on settling larvae were performed in a recirculating flume. The flume is $3.5 \mathrm{~m}$ long, $0.5 \mathrm{~m}$ wide and $0.4 \mathrm{~m}$ deep. The working section measures $0.5 \times 0.4 \mathrm{~m}$, and consists of a $0.2 \mathrm{~m}$ deep sediment box; its upstream edge is situated $2.2 \mathrm{~m}$ from the water inlet (for further details see Jonsson et al. 1991). Sediment and adult cockles were collected at a cockle bed nearby the laboratory. The sediment was sieved through a $500 \mu \mathrm{m}$ mesh to exclude macrofauna and coarse particles. The median grain diameter was $170 \mu \mathrm{m}$, as determined by size fractioning (Buchanan 1971). Flow velocity was measured using a heated thermistor probe (Vogel 1981), and velocity profiles near the bottom $(<3 \mathrm{~mm})$ were obtained from video recordings of suspended particles (Jonsson et al. 1991). Water depth in the flume during the experiments was $30 \mathrm{~cm}$. Boundary shear velocities, $u$., were calculated from the logarithmic section of the velocity profiles by fitting the velocity measurements to the velocity function described by the 'law of the wall' (Jumars \& Nowell 1984):

$$
U(z)=u \cdot / \kappa \ln \left(z / z_{0}\right)
$$

where $U(z)=$ mean downstream velocity at height $z$ above the bottom; $z_{0}=$ roughness height; and $k=$ von Karman's constant (0.4). Estimates of $u$. were then used to calculate the roughness Reynolds number, $R e$.

$$
\operatorname{Re} \cdot=u \cdot k_{\mathrm{s}} / v
$$

where $k_{\mathrm{s}}=$ bed roughness scale $(170 \mu \mathrm{m})$; and $v=$ kinematic viscosity of seawater. A summary of the flow characteristics is presented in Table 1. At all studied flows $R e$. was $<4$, and the boundary layers are thus characterized as smooth turbulent (Nowell \& Jumars 1984).

Seventy-six adult Cerastoderma edule, ca $35 \mathrm{~mm}$ in length, were placed in a regular pattern in the sediment box the distance between siphon pairs was $5 \mathrm{~cm}$. This corresponds to a density of 380 ind. $\mathrm{m}^{-2}$, which represents a fairly high density (Möller \& Rosenberg 1983). We also chose this density because it is similar to the high density treatment used in the field experiment by André \& Rosenberg (1991). The cockles readily buried themselves in the sediment, and kept their original position and orientation. In the field, there is usually no prevailing orientation of the siphons of $C$. edule in relation to flow (authors' pers. obs.). Here, we oriented all cockles with the inhalant siphon facing the flow in order to decrease variation among cockles.

Predation experiment. To investigate the fate of competent larvae that drifted over a cockle bed we added fluorescently labelled larvae downstream of the working section. The larvae were allowed to acclimate by circulating in the flume for $20 \mathrm{~min}$, after which most drifted close to the bottom, as described by Jonsson et al. (1991). Individual larvae that entered the working section (stocked with adult Cerastoderma edule) were traced by eye, and 1 of the following 4 possible outcomes was noted: inhaled, resuspended, passed the working section, or settled (a larva was considered settled when it remained motionless for more than $2 \mathrm{~min})$. For the same individual larvae we also meas-

Table 1 . Flow conditions and larval behaviour in a flume boundary-layer. $U_{\infty}$ : free-stream velocity. Boundary shear velocities $u$. $\left( \pm 95 \% \mathrm{Cl}\right.$ ) and roughness height $z_{0}$ for the 3 flows were calculated from measurements at 12,15 and 17 vertical locations respectively. Re.: roughness Reynolds number. Larval drift velocity given $\pm 1 \mathrm{SD}$. Larval drift height was calculated from mean

\begin{tabular}{|c|c|c|c|c|c|}
\hline $\begin{array}{c}U_{\infty}^{a} \\
\left(\mathrm{~cm} \mathrm{~s}^{-1}\right)\end{array}$ & $\begin{array}{c}u \cdot^{\mathrm{a}} \\
\left(\mathrm{cm} \mathrm{s}^{-1}\right)\end{array}$ & $\begin{array}{l}z_{0}{ }^{a} \\
(\mathrm{~cm})\end{array}$ & $R e$ & $\begin{array}{l}\text { Larval drift velocity }{ }^{a} \\
\qquad\left(\mathrm{~cm} \mathrm{~s}^{-1}\right)\end{array}$ & $\begin{array}{l}\text { Larval drift height } \\
\qquad(\mathrm{mm})\end{array}$ \\
\hline 2 & $0.19 \pm 0.010$ & 0.14 & 0.24 & $0.045 \pm 0.022(n=26)$ & 0.5 \\
\hline 5 & $0.22 \pm 0.018$ & 0.03 & 0.37 & $0.090 \pm 0.036(\mathrm{n}=22)$ & 0.6 \\
\hline 10 & $0.36 \pm 0.031$ & 0.003 & 0.61 & $0.16 \pm 0.060(n=40)$ & 0.3 \\
\hline
\end{tabular}
larval drift velocity using the appropriate vertical velocity profile 
ured the time elapsed from their entrance into the working section until 1 of the 4 events occurred. This experiment was done at 5 and $10 \mathrm{~cm} \mathrm{~s}^{-1}$ free-stream flow velocities

Settlement patterns of cockle larvae around feeding adults. The experiment on the distribution of settled larvae around adults was done at $10 \mathrm{~cm} \mathrm{~s}^{-1}$ free-stream velocity. Larvae were introduced downstream of the working section, and after $2 \mathrm{~h}$, when few larvae remained circulating in the flume, the distribution of settled larvae was recorded by overhead photography (Lindegarth et al. 1991). The siphon openings of 34 adult cockles could be identified on the photos. To analyze settlement patterns around individual cockles, we used a grid centred between the inhalant and exhalant siphon openings. Settlement in relation to distance from siphon openings was studied by using a concentric grid with 3 circles. The radii were $1.27,1.79$ and $2.19 \mathrm{~cm}$, giving 3 equal areas of $5 \mathrm{~cm}^{2}$. We then counted the number of settled larvae in each area. To assess the importance of location in relation to flow direction and the siphon openings, we divided the whole area into 4 sectors: upstieani, downstrcam, left and right; each sector thus had an area of $3.75 \mathrm{~cm}^{2}$. The inhalant and exhalant siphon openings occupied ca $0.11 \mathrm{~cm}^{2}$ and $0.095 \mathrm{~cm}^{2}$ respectively, and the number of settled larvae in areas containing either of the siphons was corrected accordingly. The total number of larvae that had settled around each cockle (maximum distance $2.19 \mathrm{~cm}$ from siphons) was in the range 10 to 55 . To normalize differences in settling intensity among individual cockles, the number of larvae that had settled in each area was expressed as a proportion of the total number of larvae counted around each adult. We used 1-factor analysis of variance (ANOVA) to test the statistical null hypotheses of 'no difference in proportions of settled larvae at different distances', and 'no difference in proportions of settled larvae in different sectors'. In order to avoid dependence among levels (i.e. different distances/sectors from the same individual adult) the 34 cockles were randomly divided into 3 or 4 groups. Each group then represented the replicates at 1 of the 3 distances, or 1 of the 4 sectors, making a total of 11 replicates for distances, and 8 for sectors. Since the same data set was used in the 2 different analyses, we used a corrected alpha value $\left(\alpha^{\prime}=0.025\right)$ (Sokal \& Rohlf 1981). Prior to the ANOVA we tested homoscedasticity of the variances using Cochran's test. No departure from homoscedasticity was found $(\alpha=0.05)$. Treatment means were compared using the Student-Newman-Keuls procedure ( $\alpha=0.05$ ).

Model of predation risk. We modelled the survival time for larvae drifting over a bed of adults using finitedifference computer simulation. The numerical model was written in Microsoft Basic 2.0 and run on an Apple
Macintosh II computer. The model consisted of bottom areas measuring $1 \times 1 \mathrm{~m}$, with $10,50,100,200$ or 400 adults, randomly distributed. Whenever a larva encountered a boundary of the model universe, a new bottom area was created, with a new set of adults. For each adult density we simulated 3 different flow regimes with free-stream velocities of 2,5 and $10 \mathrm{~cm}$ $\mathrm{s}^{-1}$. The resulting vertical velocity profile for each freestream velocity was constructed from actual measurements made in the flume (Table 1 ; Jonsson et al. 1991). A linear relation was used to describe the near-bottom velocity profile with slopes of $0.9,1.4$ and $5.0 \mathrm{~s}^{-1}$ for the flow speeds 2,5 and $10 \mathrm{~cm} \mathrm{~s}^{-1}$ respectively. Above ca $5 \mathrm{~mm}$ from the bottom a logarithmic velocity profile replaced the linear according to Eq. (1). Estimates of $u$. and $z_{0}$ used in the model for the different flow speeds are given in Table 1 . For each combination of adult density and flow regime, the adult siphon openings were oricnted in 2 ways; the inhalant siphon was either facing upstream (as in the flume experiments) or randomly oriented relative to the flow direction. The flow-field produced by individual adults was based on the measurements of the siphonal currents (see Figs. 2 $\& 4)$. The inhalant siphon was modelled as a point sink (Happel \& Brenner 1983), with the measured flow through the siphons (41 $\mathrm{mm}$ cockle in Fig. 3) as a boundary condition at the centre of the inhalant siphon according to:

$$
V=V_{\max } /\left(1+r^{2} a\right)
$$

where $V$ is inhalant flow velocity at distance $r_{i} V_{\max }$ is the flow velocity through the siphon; and $a$ is a constant determined by fitting Eq. (3) to the measured flow velocities $(a=0.5$ in the model $)$. The point-sink model was chosen instead of a more realistic model of flow through a finite orifice (Happel \& Brenner 1983) because of its computational simplicity. As the distance from the siphon increases, the model of flow through an orifice rapidly and asymptotically approaches the point-sink model. The point-sink representation of inhalant flow gives a slight underestimate of the predation risk. A larva was assumed to be dead at a distance $\leq 2 \mathrm{~mm}$ from the centre of the inhalant siphon opening, regardless of the free-stream velocity. Based on flume observations, a larva was considered to be entrained in the exhalant current at a distance of $4 \mathrm{~mm}$ from the exhalant siphon centre. Upon entrainment the larva was transported in the exhalant current to a height that was a function of the along-flume cross-flow according to measurements in the flume (see Fig. 4 for the function used).

Jonsson et al. (1991) showed that settling Cerastoderma edule larvae are confined to the lower part of the benthic boundary-layer, the viscous sublayer, and that horizontal drifting velocity varied with free-stream velocity. Based on these observations we calculated the height above the 
bottom at which larvae drifted horizontally (using the appropriate velocity profile, see Table 1). If larvae were displaced above this height they were assumed to descend at a net velocity of $1 \mathrm{~mm} \mathrm{~s}^{-1}$ (Jonsson et al. 1991) until they reached the appropriate drift height.

Individual larvae were introduced randomly in the model universe at a height above the bottom corresponding to the drift velocity experimentally measured (Table 1). For each time step, all forces considered to act on the larvae were evaluated: drift velocity (depending on the velocity profile), velocity of descent ( 0 or $1 \mathrm{~mm}$ $\mathrm{s}^{-1}$ ) and inhalant and exhalant currents from all adults present in the universe. The time step used in a model run was $0.01 \mathrm{~s}$; if the distance to the nearest adult was $>5 \mathrm{~cm}$, the time step was $1 \mathrm{~s}$. When a larva was inhaled the computer program stopped and the survival time was recorded. If a larva survived for $10000 \mathrm{~s}$, the run was terminated. For each combination of adult density, free-stream velocity and siphon orientation we simulated trajectories of 50 individual larvae.

\section{RESULTS}

\section{Flow field around adult cockles}

In still water Cerastoderma edule produces a fairly bilateral symmetrical flow-field, with a strong excurrent jet and a more gentle inhalant flow (Fig. 1). Sometimes, however, the exhalant flow made an angle to the vertical plane intersecting the 2 siphon centres. Maximum exhalant flow-speeds varied between 25 and $70 \mathrm{~mm} \mathrm{~s}^{-1}$. and the flow could reach a height of at least $35 \mathrm{~cm}$ in the water column. Inhalant flow-velocities were inversely proportional to the square of the distance from the siphon opening (Fig. 2). If larval swimming speed is assumed to be on the order of $1 \mathrm{~mm} \mathrm{~s}^{-1}$ (Jonsson et al. 1991) the radius of influence for individual $C$. edule would be $<1 \mathrm{~cm}$. Since the inhalant flow was almost symmetrical in still water, frontal and lateral measurements could be used to construct a surface of equal flowvelocity, approximated by half a sphere. The product of the iso-velocity area and the flow-velocity yields the pumping rate of individual $C$. edule. Fig. 3 shows the pumping rate of $C$. edule as a function of shell length.

In flowing water the vertical influence of the inhalant current was reduced, and at free-stream velocity $U_{\infty}=$ $5 \mathrm{~cm} \mathrm{~s}^{-1}$ Cerastoderma edule entrained streamlines of particles only up to a height of $4 \mathrm{~mm}$. We were not able to measure the horizontal influence of $C$. edule in flowing water, but Ertman \& Jumars (1988) used a similar set-up $\left(U_{\infty}=2.8 \mathrm{~cm} \mathrm{~s}^{-1}\right)$ and showed that the influence of the incurrent siphon of Clinocardium nuttallii was about 2 times stronger horizontally than vertically. The boundary-layer flow in the flume caused

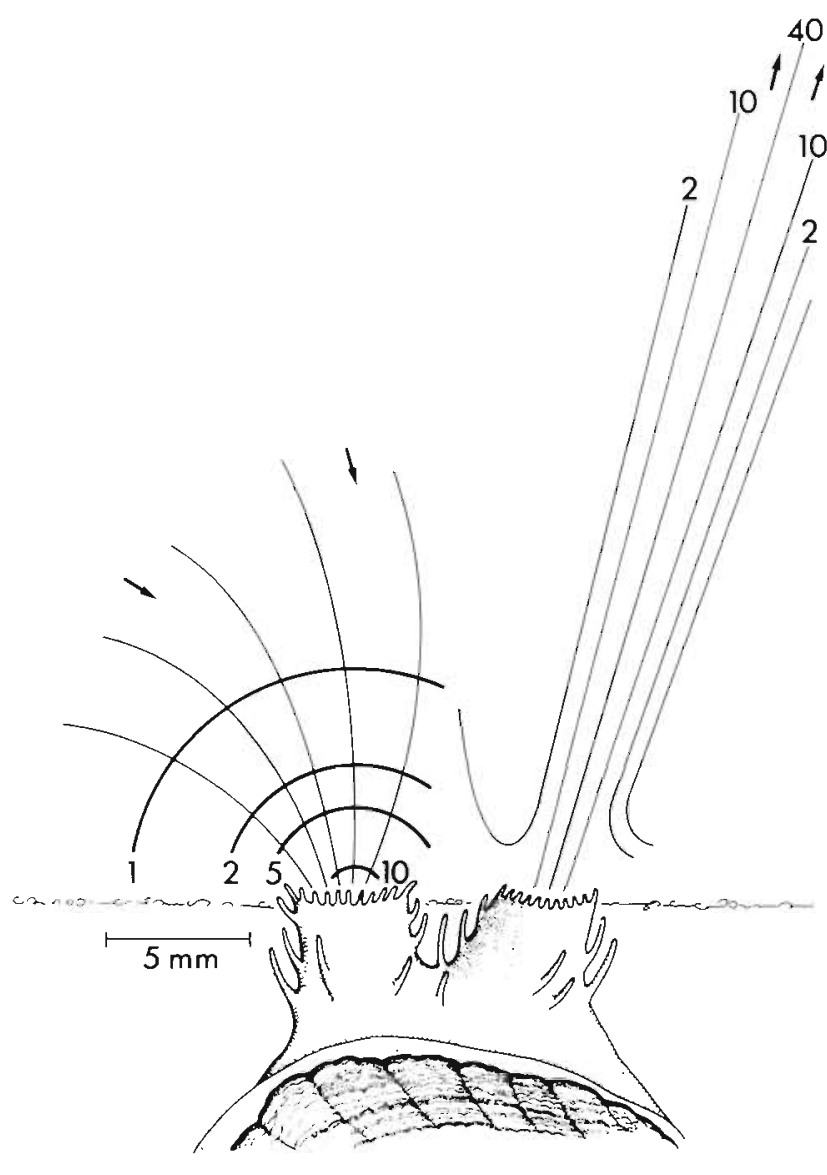

Fig. 1. Cerastoderma edule. Schematic drawing of inhalant and exhalant currents produced in still water. Numbers indicate flow velocity in $\mathrm{mm} \mathrm{s}^{-1}$ Arrows show direction of depicted flow lines; thick lines above inhalant siphon represent isolines of flow velocity $\left(\mathrm{mm} \mathrm{s}^{-1}\right)$. Since the isolines of the exhalant flow velocity are almost parallel to the flow lines at the scale of the drawing, the depicted flow lines also serve as isolines

a deflection of the exhalant jet, and at $U_{\infty}=15 \mathrm{~cm} \mathrm{~s}^{-1}$ the excurrent reached a height of less than $1 \mathrm{~cm}$ above the sediment surface $10 \mathrm{~cm}$ downstream of the siphon (Fig. 4). In both still and flowing water C. edule showed a regular feeding rhythm with continuous pumping.

\section{Predation risk}

Larvae of Cerastoderma edule suspended in the flume boundary-layer flow drifted less than $1 \mathrm{~mm}$ above the bottom in the streamwise direction. Individual larvae that entered the working section, which was stocked with feeding adult $C$. edule, were traced by eye. At both free-stream velocities, 5 and $10 \mathrm{~cm} \mathrm{~s}^{-1}$, very few larvae managed to pass the $40 \mathrm{~cm}$ long working section. The majority of larvae were inhaled, some were resus- 


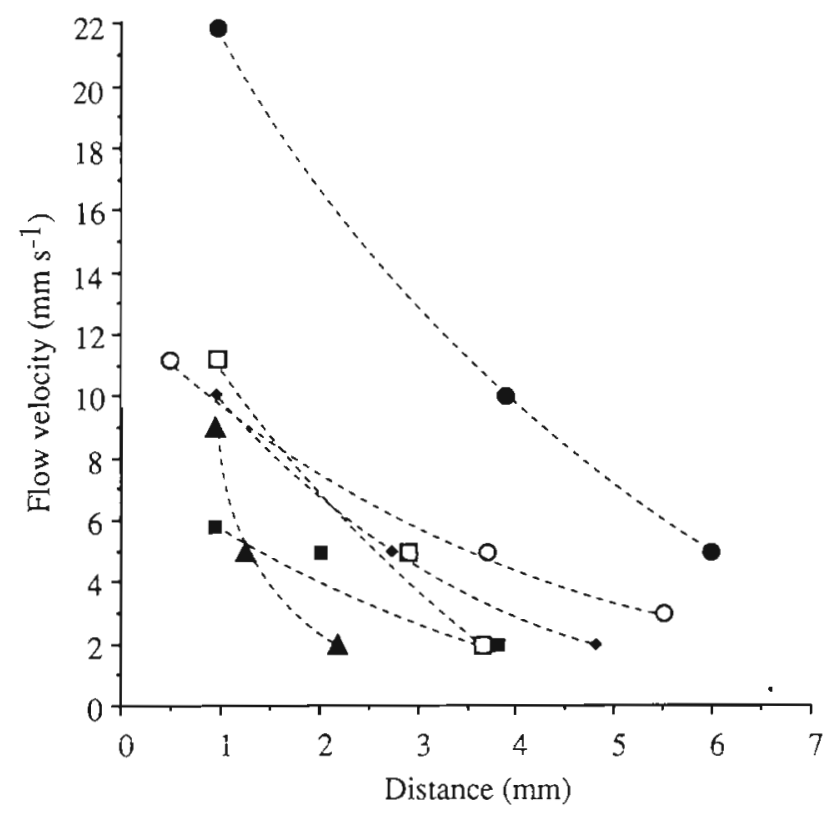

Fig. 2. Cerastoderma edule. Flow velocity of the inhalant curlent as a function of distance from siphon nnening. Each curve denotes 1 individual

pended and a few settled (Table 2). Resuspension of larvae usually occurred when a larva was caught in the excurrent jet, and was not due to turbulent eddies reaching down to the bottom.

The mean time that larvae drifted over the cockle bed in the flume before being inhaled or resuspended was around $60 \mathrm{~s}$, and did not differ between free-stream velocities (Table 3 ). The 3 larvae that passed $\left(U_{\infty}=5 \mathrm{~cm}\right.$ $\mathrm{s}^{-1}$ ) travelled across the working section in 105, 134 and $225 \mathrm{~s}$, with mean drifting velocities of $3.8,2.9$ and $1.8 \mathrm{~mm} \mathrm{~s}^{-1}$ respectively. These values are 2 to 4 times

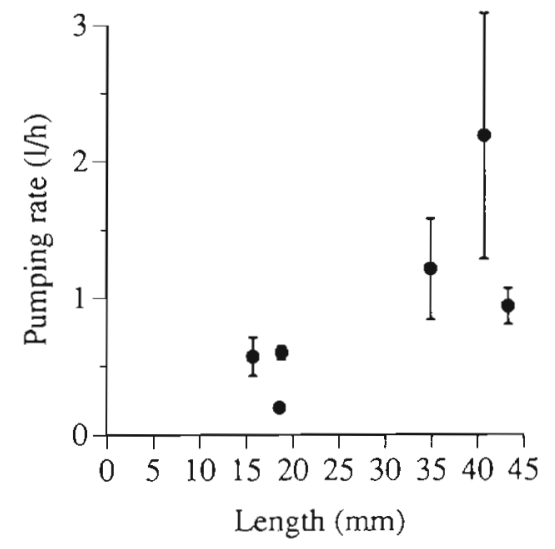

Fig. 3. Cerastoderma edule. Pumping rate (mean $\pm \mathrm{SD}$ ) in still water as a function of length. Each point represents the mean of 2 lateral and 2 frontal measurements $(n=4)$ on 1 individual ( $\Delta$ t between measurements $\approx 30 \mathrm{~min}$ )

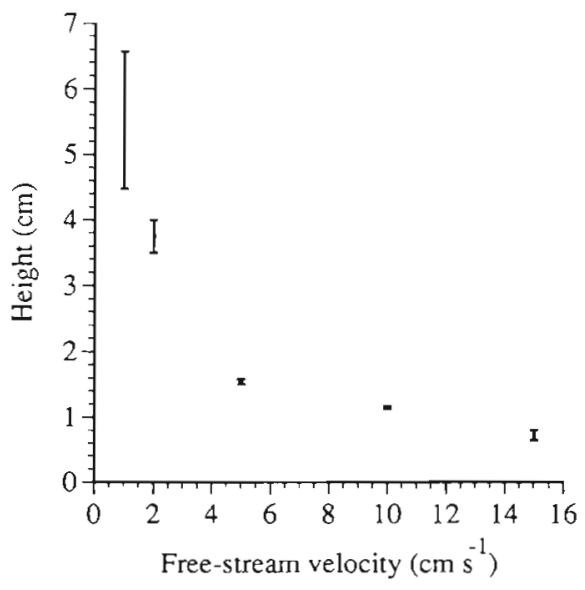

Fig. 4. Cerastoderma edule. Erosion height (mean \pm SD) of exhalant jet in flowing water, at a downstream distance of $10 \mathrm{~cm}$, as a function of free-stream velocity, for 2 individuals. The relation is described by: Height $=5.73 \times$ free-stream velocity ${ }^{0746} ; R^{2}=0.987$

higher than the mean drifting velocities in Table 1 . This may be due to selection of those larvae that drifted slightly higher (and faster) above the bottom, and were consequently less exposed to predation risk.

Finally, we collected several adult $C$. edule and examined the gut contents for the presence of larval remains. Epifluorescence microscopy showed that the guts contained fluorescent particles, and under the light microscope several individual larvae were identified in the gut contents. Most larvae had crushed shells.

\section{Settlement patterns}

The distribution of settled larvae around the adult siphon openings was recorded by photography, which showed the position of each settled larva. Significantly

Table 2. Predation experiment. Fate of individual larvae drifting over a cockle bed

\begin{tabular}{|rccccc|}
\hline $\begin{array}{c}U_{\infty} \\
\left(\mathrm{cm} \mathrm{s}^{-1}\right)\end{array}$ & Inhaled & Resuspended & Settled & Passed \\
\hline 5 & 25 & 10 & 1 & 3 & 39 \\
10 & 33 & 8 & 3 & 0 & 44 \\
\hline
\end{tabular}

Table 3. Time $\left(s_{i}\right.$ mean $\pm \mathrm{SD}$ ) until larvae were inhaled, resuspended, settied or had passed the working section Numbers of replicate larvae are shown in Table 2

\begin{tabular}{|ccccc}
\hline $\begin{array}{c}U_{\infty} \\
\left(\mathrm{cm} \mathrm{s}^{-1}\right)\end{array}$ & Inhaled & Resuspended & Settled & Passed \\
\hline 5 & $64 \pm 89$ & $67 \pm 64$ & $140 \pm 0$ & $155 \pm 63$ \\
10 & $64 \pm 63$ & $64 \pm 25$ & $70 \pm 53$ & - \\
\hline
\end{tabular}


fewer larvae settled in the inner areas compared to the central and outer areas ( $p<0.025$ ) (Fig. 5). There were, however, no differences in the proportions of larvae that settled upstream, downstream or lateral to the adults ( $p>0.025)$ (Fig. 6).

\section{Model of predation risk}

The computer model, which simulated the survival time of bivalve larvae drifting over a bed of suspension-feeding adult cockles, showed that mean survival time decreased drastically with increasing adult density (Fig. 7a). The mortality risk increased slightly with free-stream velocity, due to an increased encounter rate between drifting larvae and feeding adults (Fig. 7a). The frequency distributions of survival times were usually skewed to the left, with many larvae surviving for a short time and fewer larvae surviving for longer periods (Fig. 8). The model essen-

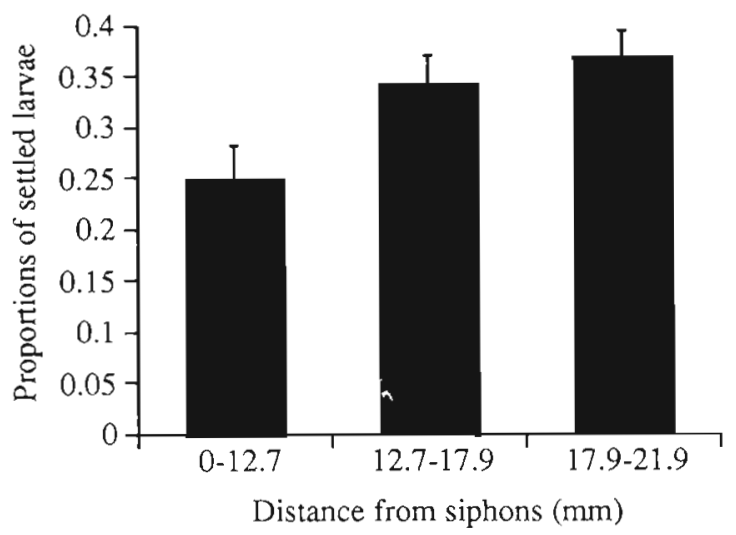

Fig. 5. Cerastoderma edule. Settling intensity (mean $\pm \mathrm{SE}$ ) of larvae with increasing distance from adult siphon openings

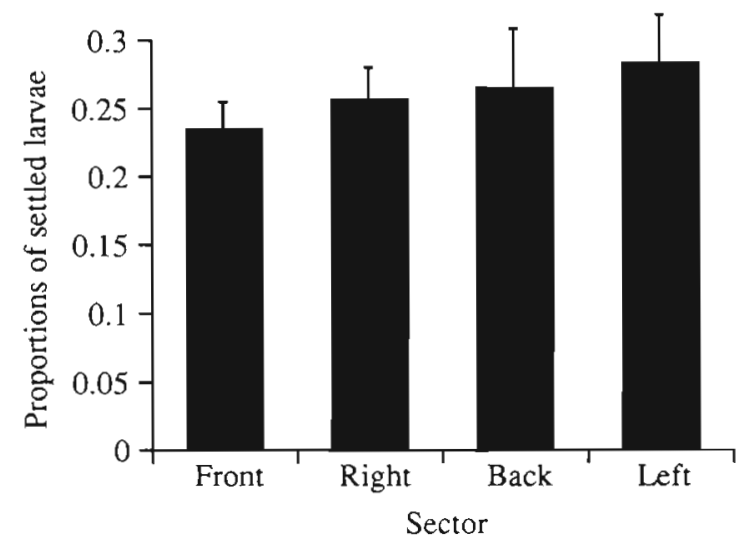

Fig. 6. Cerastoderma edule. Settling intensity (mean \pm SE) of larvae in different sectors around adult siphon openings

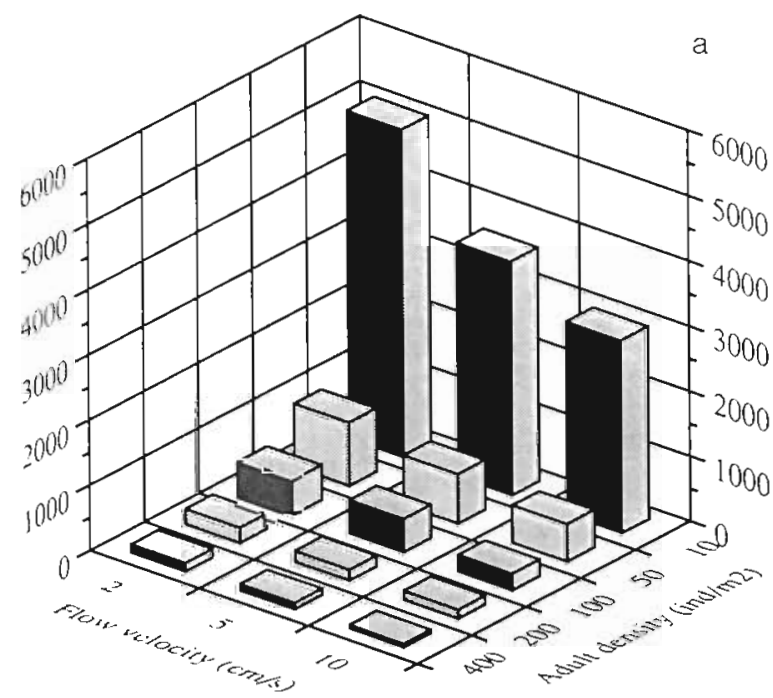

$\frac{3}{3}$

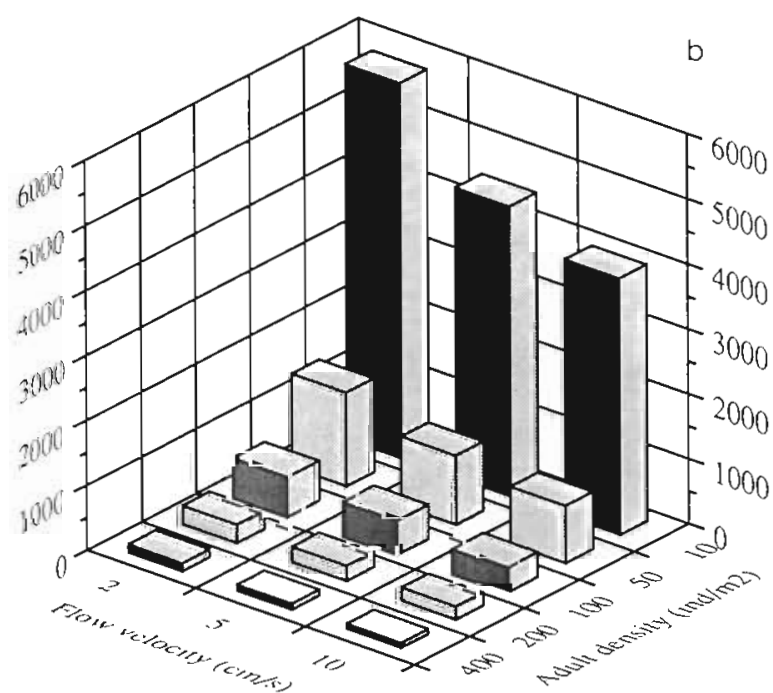

$\frac{2}{3}$

Fig. 7 Cerastoderma edule. Mean survival time of drifting larvae over a bottom with adults as a function of adult density and flow velocity. (a) Inhalant siphon located upstream of exhalant siphon. (b) Inhalant siphon located randomly in relation to exhalant siphon

tially estimates the encounter rate of randomly distributed objects. It is therefore not surprising that the distribution of survival times among larvae, as a function of adult density, show a reasonable fit to a Poisson distribution.

To assess the variation in survival we have plotted the most successful larvae, which we defined as the $10 \%$ that survived longest, for each combination of adult density and free-stream velocity (Fig. 9a). Under all flow conditions survival time decreased exponentially with increasing adult density (Fig. 9a). When all adults were oriented with their exhalant siphons downstream, drifting larvae were only occasionally caught in the exhalant jet and resuspended into the 

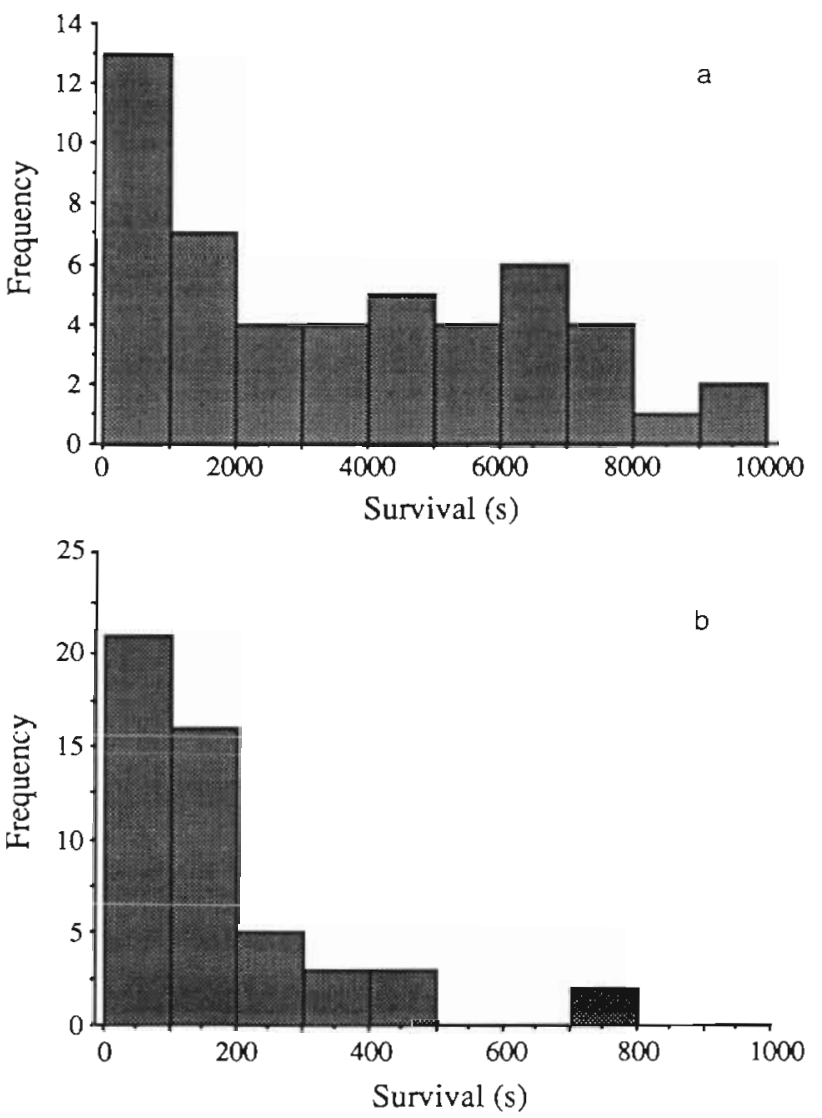

Fig. 8. Cerastoderma edule. Frequency distribution of survival time for drifting larvae over a bottom with adults at a free-stream velocity of $5 \mathrm{~cm} \mathrm{~s}^{-1}(\mathrm{n}=50)$. (a) 10 adults $\mathrm{m}^{-2}$ (b) 200 adults $\mathrm{m}^{-2}$

water column (ca 2 to $4 \%$ of the larvae in each run). When, instead, the inhalant and exhalant siphons were randomly oriented in relation to each other, resuspension of larvae by the exhalant jet was more frequent ( 20 to $40 \%$ of the larvae). However, as shown in Figs. $7 \mathrm{~b} \& 9 \mathrm{~b}$ this resulted in only slightly higher survival times.

\section{DISCUSSION}

Settlement of bivalve larvae around adults of Cerastoderma edule was reduced by $33 \%$ in an area of $5 \mathrm{~cm}^{2}$ enclosing the siphons, compared to areas further away from the siphon openings (Fig. 5). The radius of influence was thus about 1 to $1.5 \mathrm{~cm}$. It is thus not surprising that Ertman \& Jumars (1988) did not detect any effects of the suspension-feeding bivalve Clinocardium nuttallii on the sedimentation of polystyrene particles, since they did not sample closer than $2 \mathrm{~cm}$ from the siphons. It is not clear why larval settlement is reduced close to the siphons, although the most probable explanation is

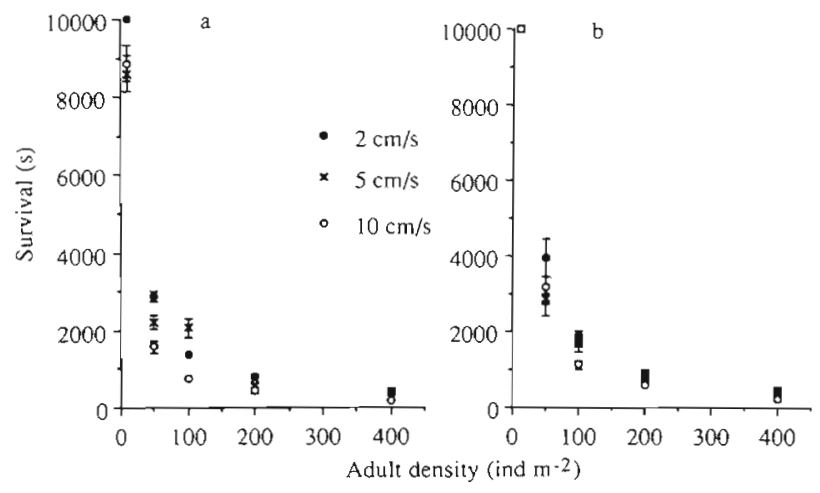

Fig. 9. Cerastoderma edule. Survival (mean \pm SE) of the $10 \%$ most successful larvae drifting over a bottom with adults as a function of adult density and flow velocity. (a) Inhalant siphon located upstream of exhalant siphon. (b) Inhalant siphon located randomly in relation to the exhalant siphon

entrainment in inhalant and exhalant currents. This was frequently observed during the experiments.

It has been suggested that the vertical location of the feeding siructure may affect the intonsity of larval settlement around individual, established suspension feeders (Young 1990). Species of suspension feeders with capture zones several $\mathrm{cm}$ above the bottom (e.g. ascidians) are less likely to produce local settlement patterns than individuals with their feeding apertures more or less flush with the bottom surface (e.g. infaunal bivalves).

Small-scale distributional patterns provide little information about the risk of predation to settling larvae from suspension feeders. Simulations of passively sinking particles in flow-fields generated by feeding bivalves indicate that settling intensity can be homogeneous although a large proportion of the particles is consumed (authors' pers. obs.). Apart from the density of suspension-feeders, the predation risk is to a large extent a function of the distribution of larvae in the water column, and this is affected e.g. by larval settlement behaviour. Two categories of settlement behaviour have been proposed in the literature (Fig. 10). In

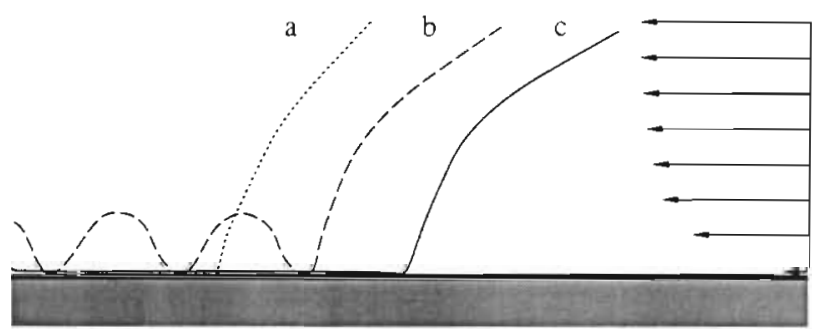

Fig. 10. Three different models of settlement behaviour of invertebrate larvae. (a) Passive deposition. (b) 'Ping-pong' or 'balloonist' behaviour. (c) Drifting behaviour. Arrows schematically indicate the velocity profile in the boundary layer 
the simplest model (Fig. 10, a) the larvae act as passive particles, which settle when encountering the substratum (Hannan 1984, Butman 1989, Eckman 1990, Young 1990). Another model of settlement behaviour has been characterized as 'balloonist' (Butman 1986) or 'ping-pong ball' (Keough \& Downes 1982) behaviour (Fig. 10, b), in which settling larvae repeatedly enter the water column after exploring the local substratum characteristics. This allows a larva to scan the substratum at a larger spatial scale while searching for a suitable settling site. Observations of larvae that drift close to the substratum, from the present study and in Jonsson et al. (1991) indicate a third type of settlement behaviour, which may be caused by hydrodynamic forces (Fig. 10, c). When the 3 types of behaviour are viewed as a continuum that represents trade-offs between the ability to search large areas effectively, and to avoid benthic suspension feeders, the third type of behaviour makes larvae extremely susceptible to predation. On the other hand, it may enable larvae to effectively scan a large area for suitable microhabitats.

Young (1990) presented a model which predicted that the maximum depletion for passively sinking larvae was only $12.5 \%$ in a habitat completely covered with barnacles. In this study, we show that the rate of predation can be substantially higher ( 75 to $80 \%$ of the observed larvae were inhaled) if larval behaviour departs from passive deposition. The mean survival time of larvae drifting through the dense bed of cockles $\left(380 \mathrm{~m}^{-2}\right)$ was only about $60 \mathrm{~s}$. This agreed well with the mean survival time from the computer simulations for a similar adult density $\left(400 \mathrm{~m}^{-2}\right)$. Even at moderate adult densities $\left(50 \mathrm{~m}^{-2}\right)$, the model yields expected mean survival times of less than $15 \mathrm{~min}$ (Fig. 7). The model also shows that survival time is not very sensitive to flow speed. This is because the increased drift velocity of larvae at higher flow speeds is partly compensated by a reduced encounter radius when larvae pass the adults at a faster speed. However, the short mean survival times may be misleading, since the distribution of survival times is strongly skewed towards longer survival times, as is expected when the probability of encounter between a larva and an adult is constant per time unit. Figs. $7 \mathrm{a} \& 8 \mathrm{a}$ show that although mean survival time at a density of 50 adults $\mathrm{m}^{-2}$ and a flow of $5 \mathrm{~cm}^{-1}$ is only $760 \mathrm{~s}, 10 \%$ of the larvae survive $2200 \mathrm{~s}$ on average. As the density of settling Cerastoderma edule is usually high, the proportion of larvae that escape predation may still result in a high density of settlers in spite of the intense predation. Estimation of the absolute risk of predation for drifting larvae requires knowledge of the time that larvae spend drifting before they decide to settle. Both the probability of encountering a predator and a suitable settling site will increase with the distance covered by drifting larvae, indicating a trade-off between predation risk and successful settlement. The further a larva drifts along the bottom, the more predators it will encounter. Future research on the amount of time that larvae spend scanning for suitable settling sites, and how this depends on environmental factors, will give important information on the absolute risk of predation for settling larvae. Our flume experiments suggest that the time spent in the drifting phase is on the order of some hours, but this probably depends on the age of the larvae and sediment properties.

Large and small-scale hydrodynamic patterns, substratum characteristics, larval behaviour and predation by resident infauna and epifauna may all act to determine larval settlement and subsequent survival. The present study suggests that large-scale $\left(10^{1}\right.$ to $\left.10^{3} \mathrm{~m}\right)$ effects on recruitment due to predation by populations of resident suspension feeders may be important, even though settlement patterns on the scale of individual adults are obscure.

Acknowledgements. We thank Cathy Hill and Fredrik Pleijel for instructive criticism on an earlier draft of this paper. The study was supported by the Swedish Natural Science Research Council through contract B-BU 1860-303 to P.R.J. and through contract B-BU 3294-303 to C.A. Additional support was provided to P.R.J., C.A. and M.L. by grants from the Helge Ax:son Johnsson, Lars Hierta and Collianders foundations and the Royal Academy of Science.

\section{LITERATURE CITED}

André, C., Rosenberg, R. (1991). Adult-larval interactions in the suspension-feeding bivalves Cerastoderma edule (L.) and Mya arenaria L. Mar. Ecol. Prog. Ser. 71: $227-234$

Bachelet, G., Guillou J., Labourg, P.-J. (1992). Adult-larval and juvenile interactions in the suspension-feeding bivalve, Cerastoderma edule: field observations and experiments. In: Colombo, G., Ferrari, I., Ceccherelli, V. U., Rossi, R. (eds.) Proc. 25th Eur. mar. Biol. Symp. Olsen \& Olsen, Fredensborg, p. 175-182

Beukema, J. J. (1976). Biomass and species richness of the macrobenthic animals living on the tidal flats of the Dutch Wadden Sea. Neth. J. Sea Res. 10: 236-261

Beukema, J. J. (1982). Annual variation in reproductive success and biomass of the major macrozoobenthic species living in a tidal flat area of the Wadden Sea. Neth. J. Sea Res. 16: 37-45

Black, R., Peterson, C. H. (1988). Absence of preemption and interference competition for space between large suspension feeding bivalves and smaller infaunal macroinvertebrates. J. exp. mar. Biol. Ecol. 120: 183-198

Buchanan, J. B. (1971). Sediments. In: Holme, N. A., McIntyre, A. D. (eds.) IBP-handbook: methods for the study of marine benthos. Blackwell, Oxford, p. 30-51

Butman, C. A. (1986). Larval settlement of soft-sediment invertebrates: some predictions based on an analysis of near bottom velocity profiles. In: Nilhoul, J. C. J. (ed.) 
Marine interfaces ecohydrodynamics. Elsevier Oceanography Series 42, Elsevier, Amsterdam, p. 487-513

Butman, C. A. (1987). Larval settlement of soft-sediment invertebrates: the spatial scales of pattern explained by active habitat selection and the emerging role of hydrodynamical processes. Oceanogr. mar. Biol. A. Rev. 25: $113-165$

Butman, C. A. (1989). Sediment-trap experiments on the importance of hydrodynamical processes in distributing settling invertebrate larvae in near-bottom waters. J. exp. mar. Biol. Ecol. 134: 37-88

Crisp, D. J. (1974). Factors influencing the settlement of invertebrate larvae. In: Grant, P. T., Mackie, A. M. (eds.) Chemoreception in marine organisms. Academic Press, London, p. 177-265

Davis, A. R., Targett, N. M., McConnell, O. J., Young, C. M. (1989). Epibiosis of marine algae and benthic invertebrates: natural products chemistry and other organisms inhibiting settlement and overgrowth. In: Bioorganic marine chemistry, Vol. 3. Springer Verlag, Berlin, p. 85-114

Davis, A. R. Wright, A. E. (1988). Ascidian antifouling defenses: surface acidity vs sernndary metaholites Am. Zool. 28: 70A

Eckman, J. E. (1990). A model of passive settlement by planktonic larvae onto bottoms of different roughness. Limnol. Oceanogr. 35: 887-901

Ertman, S. C., Jumars. P. A. (1988). Effects of bivalve siphonal currents on the settlement of inert particles and larvae. J. mar. Res. 46: 797-813

Hancock, D. A. (1973). The relationship between stock and recruitment in exploited invertebrates. Rapp. P.-v. Réun. Cons. int. Explor. Mer 164: 229-240

Hannan, C. A. (1984). Planktonic larvae may act like passive particles in turbulent near-bottom flows. Limnol. Oceanogr. 29: 1108-1116

Happel, J., Brenner, H. (1983). Low Reynolds number hydrodynamics, 2nd edn. Marcus Nijhoff Publishers, Dordrecht

Hines, A. H., Posey, M. H., Haddon, P. J. (1989). Effects of adult suspension- and deposit-feeding bivalves on recruitment of estaurine infauna. Veliger 32: 109-119

Jensen, K. T. (1992). Population dynamics and production of Cerastoderma edule on an intertidal mudflat in the Danish Wadden Sea. Neth. J Sea Res. 28: 335-345

Jonsson, P. R., André, C., Lindegarth, M. (1991). Hydrodynamic near-bottom confinement of settling marine bivalve larvae in a flume boundary-layer flow. Mar. Ecol. Prog. Ser. 79: 67-76

Jumars, P. A., Nowell, A. R. M. (1984). Fluid and sediment dynamic effects on marine benthic community structure. Am. Zool. 24:45-55

Keough, M. J., Downes, J. N. (1982). Recruitment of marine invertebrates: the role of active larval choice and early mortality. Oecologia 54: 348-354

This article was submitted to the editor
Kristensen, I. (1957). Difference in density and growth in a cockle population in the Dutch Wadden Sea. Archs. néerl. Zool. 12: 351-453

Lindegarth, M., Jonsson, P. R., André, C. (1991). Fluorescent microparticles: a new way of visualizing sedimentation. and larval settlement. Limnol. Oceanogr. 37: 1471-1476

Möller, P. (1986). Physical factors and biological interactions regulating infauna in shallow boreal areas. Mar. Ecol. Prog. Ser. 30: 33-47

Möller, P., Rosenberg, R. (1983). Recruitment, abundance and. production of Mya arenaria and Cardium edule in marine shallow waters, western Sweden. Ophelia 22: 33-55

Nowell, A. R. M., Jumars, P. A. (1984). Flow environments of aquatic benthos. A. Rev. ecol. Syst. 15: 303-328

Pawlik, J. R., Butman, C. A., Starczak, V. R. (1991). Hydrodynamic facilitation of gregarious settlement of a reefbuilding tube worm. Science 251: 421-424

Peterson, C. H., Black, R. (1987). Resource depletion by active suspension feeders on tidal flats: influence of local density and tidal elevation. Limnol. Oceanogr. 32: 143-166

Ritchoff, D., Maki, J., Mitchell, R., Costlow, J. D. (1986). Ion and neuropharmacological studies of barnacle settlement Neth. J. Sea Res. 20: 269-275

Smidt, E. L. B. (1944). The effects of ice winters on marine littoral faunas. Folia Geographica Danica 2(3): 16-20

Sokal, R. R., Rohlf, F. J. (1981). Biometry. W.H. Freeman \& Co, San Francisco

Standing, J. D., Hooper, I. R, Costlow, J. D. (1984). Inhibition and induction of barnacle settlement by natural products present in Octocorals. J. chem. Ecol. 10: 823-834

Thorson, G. (1950). Reproductive and larval ecology of marine bottom invertebrates. Biol. Rev. 25: 1-45

Vogel, S. (1981). Life in moving fluids. Willard Grant Press, Boston

Woodin, S. A. (1976). Adult-larval interactions in dense infaunal assemblages: patterns of abundance. J. mar. Res. 34: $25-41$

Woodin, S. A. (1985). Effects of defecation by arenicolid polychaete adults on spionid polychaete juveniles in field experiments: selective settlement or differential mortality. J. exp. mar. Biol. Ecol. 87: 119-132

Young, C. M. (1990). Larval predation by epifauna on temperate reefs: scale, power and scarcity of measurable effects. Aust. J. Ecol. 15: 413-426

Young, C. M., Chia, F.-S. (1981). Laboratory evidence for delay of larval settlement in response to a dominant competitor. Int. J. Invert. Reprod. 3: 221-226

Young, C. M., Chia, F.-S. (1987). Abundance and distribution of pelagic larvae as influenced by predation, behavior and hydrographic factors. In: Giese, A. C. (ed.) Reproduction of marine invertebrates. General aspects: seeking unity in diversity. The Boxwood Press, Pacific Grove, CA, p. $385-463$ 